\title{
Spruce budworm feeding and oviposition are stimulated by monoterpenes in white spruce epicuticular waxes
}

\author{
Darragh Ennis ${ }^{1}$, Emma Despland ${ }^{1}$, Fei Chen ${ }^{2}$, Pat Forgione ${ }^{2}$ and Eric Bauce ${ }^{3}$ \\ ${ }^{1}$ Department of Biology; ${ }^{2}$ Department of Chemistry and Biochemistry, Concordia University, Montreal H4B 1 R6 and ${ }^{3}$ Département des \\ Sciences du bois et de la forêt, Université Laval, Québec City, Quebec, Canada
}

\begin{abstract}
Monoterpenes, source of the distinctive odor of conifers, are generally considered plant defensive compounds. However, they are also known to act as long-range insect attractants, as they are volatile and permeate forest airspaces. Moreover, they are lipid soluble and can be absorbed into plant epicuticular waxes. We test their role in short-range host plant choice by both adult females and larvae of a folivorous forest pest (Choristoneura fumiferana). We conducted laboratory assays testing the responses of Eastern spruce budworm to an artificial monoterpene mix ( $\alpha$-pinene, $\beta$-pinene, limonene, myrcene) and to white spruce (Picea glauca) epicuticular waxes in closed arenas. Ovipositing females preferred filter paper discs treated with P. glauca waxes to controls, and preferred the waxes + monoterpenes treatment to waxes alone. However, females showed no preference between the monoterpene-treated disc and the control when presented without waxes. Feeding larvae prefered wax discs to control discs. They also consumed discs treated with realistic monoterpene concentrations and wax preferentially over wax-only discs, but showed no preference between extremely high monoterpene concentrations and wax-only controls. In an insect-free assay, $P$. glauca epicuticular wax decreased monoterpene volatilization. These results suggest that $P$. glauca waxes and realistic concentrations of monoterpenes are stimulatory to both egg-laying females and feeding larvae, and that their effects are synergistic.
\end{abstract}

Key words Choristoneura fumiferana; epicuticular waxes; monoterpenes; natural defense; oviposition; Picea glauca

\section{Introduction}

Monoterpenes are found in many tissues in conifers and are generally thought of as defensive chemicals. They clearly play an important part in oleoresin defense against stem-feeding bark beetles (Seybold et al., 2006), but their role in defense against folivorous caterpillars is less well established. Studies suggest that the notorious defoliating budworms (Choristoneura species) exhibit poorer performance on trees with high monoterpene concentrations in

Correspondence: Emma Despland, Department of Biology, Concordia University, 7141 Sherbrooke West, Montreal H4B 1R6, Quebec, Canada. Tel 514848 2424; fax: 514848 2881; Email: Emma.Despland@concordia.ca the foliage (Redak \& Cates, 1984; Cates \& Redak, 1986; Bauce et al., 1994; Carisey \& Bauce, 1997; Fuentealba \& Bauce, 2012).

However, monoterpenes are also insect olfactory attractants: they are highly volatile, and emissions from foliage pervade the airspace of conifer trees, producing the distinctive odor of boreal forests. While it has been suggested that conifer monoterpenes could attract natural enemies of herbivores as has been shown in several angiosperm systems (Huber et al., 2004), it is clear that they attract the herbivores themselves. C. fumiferana larvae (Ascoli \& Albert, 1985) and moths (Hanover, 1975) orient toward the smell of monoterpenes. C. fumiferana moths oviposit more near a source of monoterpenes (a blend of $\alpha$-pinene, $\beta$-pinene, camphor, limonene, myrcene, thujone). Choice 
tests among the compounds listed above show no clear preferences between them, suggesting that monoterpene emissions act as a general long-distance host recognition cue to attract flying female budworm moths (Städler, 1974; Grant et al., 2007).

In light of this complex relationship, we test the role of monoterpenes in short-range acceptance of the host tree Picea glauca by both larvae and adult females of C. fumiferana. P. glauca has at least 69 unique and transcriptionally active genes for terpene synthases, and most of these are involved in the synthesis of several different terpenoid products (Keeling et al., 2011). Monoterpenes are synthesized in plastids in foliar mesophyll cells and are stored in resin ducts in leaves and stems. They diffuse out from the mesophyll cells, in proportion to the vapor pressure inside the needle, mostly during the day as their synthesis is light sensitive. Monoterpenes are emitted from the needles through the stomata but also slightly through the cuticle (Lerdau et al., 1997). However, foliar epicuticular waxes can influence the emission of monoterpenes as well as retain them at the needle surface (Steinbauer \& Davies, 2004). Indeed, monoterpenes are lipid soluble and can be absorbed into the epicuticular wax layer of the needle (Muller \& Riederer, 2005). The surface of conifer needles is coated with wax made mostly of nonacosan10 -ol that forms tubular aggregates, mixed with a variety of nonvolatile organic compounds including carboxyl acids, alcohols, alkanes and phenolics (Gordon \& Riding, 1998; Matas et al., 2003). Monoterpenes have been detected in epicuticular waxes of several spruce species, including P. glauca (Pruegel \& Lognay, 1996; Bourdier, 2012).

When an insect contacts a needle with its taste sensilla, either on the mouthparts in the case of a feeding larva or on the ovipositor in the case of a laying adult female, both the waxes themselves and the compounds dissolved in them provide chemical cues which could either stimulate or deter further feeding or oviposition. Feeding by C. fumiferana larvae is stimulated on paper discs treated with host waxes (Maloney et al., 1988) and hexane extracts (Albert \& Parisella, 1985, 1988; Albert, 1991) relative to controls. Larvae both palpate for less time and are more likely to initiate feeding on intact foliage than on dewaxed foliage (Daoust et al., 2010), suggesting that plant waxes mediate cues for host recognition and feeding initiation.

Similarly, C. fumiferana moths oviposit more on discs treated with host plant waxes (Rivet \& Albert, 1990; Wallace et al., 2004) and with hexane host plant extracts (Grant \& Langevin, 1994), suggesting that host cues are generally stimulatory. Prior to oviposition, females drum the surface with the legs and probe with the ovipositor, and these behaviors are thought to involve detecting surface chemicals in order to make a decision about the suitability of the substrate for oviposition (Wallace et al., 2004). Indeed, the $C$. fumiferana ovipositor contains gustatory chemosensilla that respond to sucrose, but their sensitivity to other compounds, like monoterpenes, has not been tested (Banga et al., 2003).

Thus, it seems clear that host plant waxes act as contact stimulants to feeding larvae and egg-laying females. These waxes contain monoterpenes (Pruegel \& Lognay, 1996; Bourdier, 2012), but it is not clear whether these monoterpenes influence the behavior of $C$. fumiferana caterpillars or moths contacting the plant surface.

In this study, we test how short-range contact chemoreception of host waxes and monoterpenes influences C. fumiferana oviposition and feeding behavior. Monoterpenes are presented to insects on cellulose discs in a two-choice set-up in a closed arena. Monoterpenes are presented both with and without host waxes to examine the possibility that, as proposed by Steinbauer and Davies (2004), wax compounds interact with monoterpenes.

\section{Materials and methods}

\section{Oviposition assays}

C. fumiferana were received as diapausing 2 nd instar larvae from the Great Lakes Forest Research Centre (Canadian Forest Service) and reared in $30 \mathrm{~mL}$ solo cups on artificial diet (Grisdale \& Wilson, 1988) in an incubator under a $16 \mathrm{~L}: 8 \mathrm{D}$ photoperiod at $22{ }^{\circ} \mathrm{C}$ and $60 \%$ relative humidity. Pupae were removed from the rearing chambers and kept individually in similar containers under the same conditions until eclosion. Each adult female was placed with 2 males in a $1 \mathrm{~L}$ mating chamber for $24 \mathrm{~h}$. Females were then transferred to the two-choice bioassay.

Two-choice tests were conducted in closed arenas to limit volatilization of monoterpenes and limit the possibility of concentration gradients that could elicit confounding olfactory responses (Powell \& Raffa, 2003). The arenas were made of 3 round containers $(12 \mathrm{~cm}$ diameter, $8 \mathrm{~cm}$ deep) glued together with $3 \times 3 \mathrm{~cm}$ openings cut between the 2 end chambers and the central chamber.

Four different test solutions were combined in 3 twochoice combinations: (i) control versus wax (hexane vs. hexane + epicuticular waxes), (ii) wax versus wax + terpenes (hexane + epicuticular waxes vs. hexane + waxes + monoterpene mix), and (iii) control versus terpenes (Hexane vs. hexane + monoterpene mix). The epicuticular wax extract was obtained by soaking 50 fresh needles collected from several $P$. glauca trees in a 40 year-old 
plantation near Drummondville (Canada) in $1 \mathrm{~mL}$ hexane for $60 \mathrm{sec}$. The monoterpene mix was made of equal parts $\alpha$-pinene, $\beta$-pinene, myrcene and limonene, dissolved in a $1: 5$ monoterpenes : hexane solution (Sigma Aldrich Ltd, Oakville, Canada). These compounds were chosen as they are the main components of the monoterpene mix in the epicuticular waxes of trees in this plantation (Bourdier, 2012).

Whatman grade 31 filter paper discs $(55 \mathrm{~mm}$ diameter, $190 \mathrm{mg}$ ) were placed as oviposition substrates in $55 \mathrm{~mm}$ Petri dish lids. First, $100 \mu \mathrm{L}$ of the wax solution (or the hexane control) was pipetted onto a filter paper disc and placed in the fume hood for $2 \mathrm{~h}$ to evaporate the hexane. Subsequently, $100 \mu \mathrm{L}$ of monoterpene mix solution was applied to the test disc (or hexane only for the controls). One Petri dish lid was placed in each end chamber of the 3 chamber assay arena. The final concentration of monoterpenes on the paper discs is $58 \mathrm{mg} / \mathrm{g}$, which is close to the top of the range of total monoterpene concentrations measured in P. glauca foliage (Mattson et al., 1991; Fuentealba \& Bauce, 2012).

For each of the 3 choice combinations, 12 replicate arenas were set up; 1 mated female was placed in the central chamber of the 3 chamber arena and left for $48 \mathrm{~h}$. The insects were then removed and the eggs in each chamber were counted. The number of egg masses on each disc reflects attraction and can include both olfactory and contact cues, whereas the size of egg masses reflects stimulation of oviposition by contact cues (Städler, 1974; Grant \& Langevin, 1994; Wallace et al., 2004). We compared the following variables between the 2 discs presented together: number of eggs, number of egg masses, and size of egg masses (average number of eggs per mass). For all 3 dependent variables, the data did not follow either the normal or the Poisson distribution, but rather were overdispersed. However, the differences between values on the 2 sides of the arena did follow a Gaussian distribution, and therefore these were compared to zero with one-sample $t$-tests. The power of the test is calculated as 1 minus the Type II error rate given in the standard table as associated with the experimental $t$-value.

Subsequent control tests were done with the oviposition arenas to monitor monoterpene volatilization rate. A filter paper treated with $100 \mu \mathrm{L} 1: 5$ limonene in hexane solution, with either $100 \mu \mathrm{L}$ of the wax solution or hexane as above, was placed in 1 end-chamber of the arena. The arena airspace was sampled after $30 \mathrm{~min}$ and again after $5 \mathrm{~h}$. Then, $100 \mathrm{~mL}$ of air (two $50 \mathrm{~mL}$ samples) were drawn through a syringe and bubbled through $5 \mathrm{~mL}$ hexane. Gas chromatograph-mass spectral analyses (GC-MS) were obtained using an Agilent (Mississauga, Canada) 7890A GC system and Agilent 5975C VL MSD with Triple-Axis Detector MS with a HP-588 column coated with (5\%-phenyl)-methylpolysiloxane. The calibration curve was constructed based on two $3-\mu \mathrm{L}$ injection of each of 5 standard solutions $(1.55,15.5,92.9$, 185 , and $310 \mu \mathrm{mol} / \mathrm{L}$ ) into the GC-MS and using the FID signals.

\section{Feeding assays}

A similar assay was used to offer larvae a choice between discs treated with $P$. glauca wax and various concentrations of the monoterpene mix. Larvae were reared as above until the 6th and final instar, on either the artificial diet or on P. glauca foliage collected from the same plantation. These different rearing diets were used since previous exposure to plant secondary metabolites can decrease taste responses to these compounds (Bernays, 1995).

Test solutions were prepared as above, except the monoterpene mix was diluted in hexane at a range of different concentrations. $15 \mu \mathrm{L}$ of each of the appropriate solutions were added as above (first the wax solution then the monoterpene solution, according to the treatments) to smaller discs of Sartorius cellulose nitrate filter paper ( $7 \mathrm{~mm}$ diameter, $1.8 \mathrm{mg}$ ). Five combinations were used: (1) hexane (as control) versus hexane + epicuticular waxes, (2)-(5) hexane + epicuticular waxes versus hexane + epicuticular waxes + monoterpene mix at ratio $1: 20,1$ : $10,1: 5$, or $1: 3$. The final concentrations of monoterpenes on the paper discs were $48,95,187$, and $278 \mathrm{mg} / \mathrm{g}$. These concentrations begin within the physiological range for P. glauca (Mattson et al., 1991; Fuentealba \& Bauce, 2012), and the highest level corresponds to that at which Mattson (1991) detected toxic effects of some monoterpenes when added to artificial diet. Bioassays were conducted under the same conditions as rearing.

A freshly moulted 6th instar larva was placed in an arena with 2 discs pinned to a styrofoam floor covered by a $9 \mathrm{~cm}$ diameter Petri dish. After $48 \mathrm{~h}$, the proportion of each disc consumed was recorded as an index of taste responses (Maloney et al., 1988). A total of 20 artificial diet-reared insects and 30 foliage-reared insects were used for each choice combination. Analysis involved one-sample $t$-tests on the difference in consumption of the 2 discs offered, as above.

\section{Results}

\section{Oviposition assays}

All females laid some eggs on both discs, so $n=12$ for all 3 combinations. In all cases, most ( $>80 \%)$ egg masses 
Table 1 Oviposition behavior of $C$. fumiferana in the 3 two-choice combinations: (1) control versus $P$. glauca wax, (2) P. glauca wax versus wax + monoterpene mix, and (3) control versus monoterpene mix. Values given are the mean and associated standard error $(n=12)$ for the number of eggs laid on each disc, the number of egg masses and the size of egg masses. Preference is evaluated with a one-sample $t$-test with 11 degrees of freedom; the test statistic, $P$-value and associated power are given for each combination.

\begin{tabular}{|c|c|c|c|c|c|c|c|c|c|c|c|c|c|}
\hline & \multirow{2}{*}{ Treatment } & \multicolumn{4}{|c|}{ Number of eggs } & \multicolumn{4}{|c|}{ Number of egg masses } & \multicolumn{4}{|c|}{ Size of egg masses } \\
\hline & & Mean $\pm \mathrm{SE}$ & $t_{11}$ & $P$ & $1-\beta$ & Mean $\pm \mathrm{SE}$ & $t_{11}$ & $P$ & $1-\beta$ & Mean $\pm \mathrm{SE}$ & $t_{11}$ & $P$ & $1-\beta$ \\
\hline \multirow[t]{2}{*}{1} & Control & $14.50 \pm 5.18$ & 2.67 & $0.02^{*}$ & 0.44 & $3.42 \pm 2.13$ & 1.69 & 0.12 & 0.21 & $5.92 \pm 2.24$ & 2.32 & $0.04^{*}$ & 0.6 \\
\hline & Wax & $27.60 \pm 7.35$ & & & & $2.83 \pm 0.98$ & & & & $13.95 \pm 4.89$ & & & \\
\hline \multirow[t]{2}{*}{2} & Wax & $11.20 \pm 6.94$ & 2.81 & $0.02^{*}$ & 0.7 & $2.77 \pm 0.02$ & 2.77 & $0.019^{*}$ & 0.46 & $8.33 \pm 5.40$ & 2.8 & $0.02^{*}$ & 0.47 \\
\hline & Wax + terpenes & $36.90 \pm 10.3$ & & & & $3.33 \pm 1.57$ & & & & $16.70 \pm 5.24$ & & & \\
\hline \multirow[t]{2}{*}{3} & Control & $21.50 \pm 7.57$ & 0.9 & 0.38 & 0.09 & $2.62 \pm 0.93$ & 0.17 & 0.87 & 0.03 & $9.46 \pm 4.26$ & 0.66 & 0.52 & 0.06 \\
\hline & Terpenes & $31.80 \pm 11.25$ & & & & $2.15 \pm 0.82$ & & & & $12.50 \pm 3.81$ & & & \\
\hline
\end{tabular}

$* P<0.05$.

were laid on the discs. The mean number of eggs laid in the central compartment where the female was released did not differ significantly between treatments (control vs. wax: $4.67 \pm 1.53 \mathrm{SD}$; wax vs. wax + terpenes: $7.08 \pm 2.66$ SD; control vs. terpenes: $5.70 \pm 2.16$ ). These eggs were not considered in the analyses. There were no significant differences between treatments in total number of eggs per female (control vs. wax: $52.1 \pm 33.15$ SD; wax vs. wax + terpenes: $55.9 \pm 22.57 \mathrm{SD}$; control vs. terpenes: $48.2 \pm$ $32.55 \mathrm{SD}$ ), in total number of egg masses (control vs. wax: $2.46 \pm 2.98$ SD; wax vs. wax + terpenes: $3.12 \pm 3.62$ SD; control vs. terpenes: $1.92 \pm 4.06 \mathrm{SD}$ ) or in average egg mass size (control vs. wax: $11.59 \pm 13.83$ SD; wax vs. wax + terpenes: $9.94 \pm 13.52 \mathrm{SD}$; control vs. terpenes: $12.49 \pm 18.54)$.

Female $C$. fumiferana preferred to lay on discs containing $P$. glauca waxes: the number of eggs and size of egg masses was significantly higher than on control discs. The number of egg masses did not differ significantly between the discs (Table 1).

Females additionally preferred discs with both epicuticular waxes and monoterpenes to discs treated with waxes alone: significant differences were observed in number of eggs, number of egg masses and size of egg masses (Table 1). These results show that both $P$. glauca epicuticular waxes and monoterpenes, when combined, act as oviposition stimulants for C. fumiferana.

However, when monoterpenes were presented without waxes, there was no preference between treated and control discs in terms of number of eggs, number of egg masses or size of egg masses (Table 1).

Subsequent trials using empty arenas with the same setup demonstrated an effect of wax on the volatilization rate of monoterpenes. GC-MS analysis of the airspace in the middle chamber showed a concentration of $329 \mu \mathrm{mol} / \mathrm{L}$
(95\% CI 230-426, $n=5$ ) for the plain monoterpene treatment and $104 \mu \mathrm{mol} / \mathrm{L}(95 \%$ CI $54-152, n=5)$ for the samples with waxes after $30 \mathrm{~min}$, and $13 \mu \mathrm{mol} / \mathrm{L}(95 \%$ CI $11.8-13.8, n=5)$ for the plain monoterpenes and $3.0 \mu \mathrm{mol} / \mathrm{L}(95 \%$ CI $2.7-3.9, n=5)$ for the samples with waxes after $5 \mathrm{~h}$. Thus, in the absence of epicuticular waxes, monoterpenes volatilize to a greater extent.

\section{Feeding assays}

The larvae that did not feed and those that finished both their discs were excluded from results, so the sample size varies between choice combinations.

Artificial diet-reared insects preferred wax-treated discs to controls, and discs with waxes and $48 \mathrm{mg} / \mathrm{g}$ monoterpenes to those with waxes only. However, they showed a slight preference for wax only discs relative to those with high concentrations of monoterpenes (significant for the $95 \mathrm{mg} / \mathrm{g}$ treatment, not significant for the 187 or $278 \mathrm{mg} / \mathrm{g}$ treatments - see Table 2). There was no significant difference between choice combinations in total consumption of both discs presented (between $46 \%$ and $72 \%$ of a single disc in all 5 cases).

Foliage-reared larvae exhibited a somewhat different pattern. Similar to the artificial diet-reared larvae, they preferred wax-treated discs to controls and discs with waxes and $48 \mathrm{mg} / \mathrm{g}$ monoterpenes to those with waxes only. However, they exhibited no preference when presented with a choice between waxes only and waxes with 95,187 , or $278 \mathrm{mg} / \mathrm{g}$ monoterpenes (Table 2). No difference was observed between combinations in the total consumption of both discs (between $43 \%$ and $73 \%$ of a single disc in all 5 cases).

These results show that waxes and realistic concentrations of monoterpenes are phagostimulatory to 
Table 2 Feeding behavior of $C$. fumiferana reared on artificial diet or foliage in the 5 two-choice combinations: (1) control versus P. glauca wax, (2)-(5) P. glauca wax versus wax + monoterpene mix (mg/g). Values given are the mean and associated standard error of the proportion of each disc consumed. Preference is evaluated with a one-sample $t$-test; the sample size, test statistic, $P$-value and associated power are given for each combination.

\begin{tabular}{|c|c|c|c|c|c|c|c|c|c|c|c|}
\hline & \multirow{2}{*}{ Treatment } & \multicolumn{5}{|c|}{ Diet-reared } & \multicolumn{5}{|c|}{ Foliage-reared } \\
\hline & & $\%$ eaten & $N$ & $t$ & $P$ & $1-\beta$ & $\%$ eaten & $n$ & $t$ & $P$ & $1-\beta$ \\
\hline \multirow[t]{2}{*}{1} & Control & $10.3 \pm 3.33$ & 17 & 2.72 & $0.006^{* *}$ & 0.6 & $17.0 \pm 5.32$ & 29 & 2.11 & $0.034^{*}$ & 0.41 \\
\hline & Wax & $43.5 \pm 7.89$ & & & & & $38.1 \pm 5.81$ & & & & \\
\hline \multirow[t]{2}{*}{2} & Wax & $16.0 \pm 4.31$ & 15 & 3.33 & $0.001^{* * *}$ & 0.71 & $6.0 \pm 1.30$ & 26 & 3.50 & $0.0001^{* * *}$ & 0.78 \\
\hline & $W+48$ & $56.3 \pm 5.84$ & & & & & $30.8 \pm 5.13$ & & & & \\
\hline \multirow[t]{2}{*}{3} & Wax & $40.6 \pm 6.98$ & 18 & 3.60 & $0.0001^{* * *}$ & 0.79 & $43.3 \pm 7.31$ & 21 & 1.69 & 0.09 & 0.36 \\
\hline & $W+95$ & $5.0 \pm 2.29$ & & & & & $21.4 \pm 4.90$ & & & & \\
\hline \multirow[t]{2}{*}{4} & Wax & $40.0 \pm 9.25$ & 12 & 1.24 & 0.34 & 0.21 & $29.0 \pm 6.30$ & 25 & 1.61 & 0.10 & 0.3 \\
\hline & $W+187$ & $26.2 \pm 6.83$ & & & & & $44.6 \pm 6.52$ & & & & \\
\hline \multirow[t]{2}{*}{5} & Wax & $31.2 \pm 7.31$ & 12 & 1.21 & 0.22 & 0.33 & $26.1 \pm 5.25$ & 27 & 0.01 & 0.91 & 0.14 \\
\hline & $W+278$ & $18.7 \pm 7.31$ & & & & & $24.1 \pm 4.04$ & & & & \\
\hline
\end{tabular}

$* P<0.05, * * P<0.01, * * * P<0.001$.

C. fumiferana larvae regardless of rearing diet. They also suggest that artificial diet-reared larvae are more sensitive to monoterpenes, since they are deterred by high concentrations of monoterpenes that do not seem to affect their foliage-reared counterparts.

\section{Discussion}

Our results confirm the stimulatory role of $P$. glauca foliar epicuticular waxes on $C$. fumiferana larval feeding and female oviposition and further demonstrate a positive effect of monoterpenes beyond that of the waxes. We also show that waxes influence the volatilization of monoterpenes and the way in which insects respond to monoterpenes, suggesting synergistic effects and highlighting the importance of considering the volatile and lipid-soluble nature of these compounds.

In our experiments, realistic levels of monoterpenes stimulated feeding by both artificial diet-reared and foliage-reared insects. In the presence of unnaturally high monoterpene levels, diet-reared insects preferred the control disc, whereas foliage reared insects showed no preference. Similarly, pine engraver beetles also accept monoterpenes more after prior exposure (Wallin \& Raffa, 2002), and in general, diet-reared insects are expected to be more sensitive to compounds to which they are naive (Bernays, 1995). Foliage-reared insects tested with high monoterpene concentrations showed neither a preference for the control disc, nor a decrease in total consumption, suggesting an absence of postingestive toxic effects of monoterpenes within the $48 \mathrm{~h}$ time frame of the assay.

Similarly, increased oviposition in the presence of host plant waxes observed in the present experiment is consistent with previous research (Rivet \& Albert, 1990; Wallace et al., 2004), but could be due to a variety of wax components, some of which, notably carboxyl acids, have been shown to be stimulatory (Grant et al., 2000). We show that monoterpenes per se also have a stimulatory effect on oviposition. Previous work showing that female C. fumiferana are attracted to monoterpenes (Grant et al., 2007) was done in open arenas, with no direct contact between the moth and the monoterpene source, and suggested long-range olfactory attraction. Our results, particularly the increase in the size of egg masses laid in the presence of waxes and monoterpenes, suggest that monoterpenes stimulate oviposition at short-range, via contact chemoreception.

Our experiments were done in small closed arenas, and chemical analysis showed very high airspace monoterpene concentrations, several orders of magnitude above airspace concentrations measured in conifer forests (typically less than $1 \mathrm{nmol} / \mathrm{L}$; Tingey et al., 1991; Hellen et al., 2012) The feeding experiment (done in $20 \mathrm{~mL}$ closed but not sealed Petri dishes) showed a preference for monoterpenes at low concentrations but no choice at high, suggesting that too high airspace concentrations interfere with choice. Similarly, the oviposition experiment (done in $1400 \mathrm{~mL}$ closed arenas) demonstrated a preference for monoterpenes when presented in wax, but none without, when airspace monoterpene concentrations are 
higher. There is therefore a synergistic effect between the insect's responses to waxes and to monoterpenes, possibly linked to stimulatory effects of other wax components or to interactions of the monoterpenes with wax components. A similar study with autumn gum moths shows that females prefer to lay on waxy than on glossy phenotypes of the eucalyptus host. Although both trees have similar monoterpene profiles in the foliage, waxy leaves are coated with a thicker and more complex wax layer. Female moths show electroantennogram responses to these monoterpenes and the authors suggest they use them in preferentially laying on waxy hosts (Steinbauer \& Davies, 2004). Our results provide further evidence of the important role of leaf epicuticular waxes in mediating insect responses to specific plant compounds at the surface of the leaf (Espelie et al., 1991; Eigenbrode \& Espelie, 1995).

Monoterpenes are both volatile and lipid soluble and therefore the interaction between monoterpene concentrations in foliage, in waxes and in tree headspace is complex, and each of these compartments can affect insects. Monoterpene emissions are known to act as long-distance $C$. fumiferana attractants, and we present evidence that monoterpenes in epicuticular waxes stimulate both adult and larval $C$. fumiferana upon contact with the needle. Monoterpenes within foliage could also have postingestive effects on feeding larvae; however, our feeding experiment suggests that ingestion of extremely high monoterpene concentrations does not decrease consumption rate, at least within $48 \mathrm{~h}$. We cannot speculate, however, about potential longer term effects of monoterpene consumption on larval growth or development. There are reports of decreased digestibility of monoterpene-rich foliage by C. fumiferana, without a decrease in consumption rate, suggesting a postingestive toxic effect (Carisey \& Bauce, 1997; Fuentealba \& Bauce, 2012). However, experiments with monoterpenes added to artificial diet variously show effects on performance to be either negative at physiological concentrations (Kumbasli \& Bauce, 2013), negative at extreme concentrations only (Mattson et al., 1991; Clancy, 2002), absent (Mattson et al., 1991) or even positive (Cates et al., 1987). Thus the toxicity of monoterpenes to caterpillars remains unproven, and their mode of action is unclear (Gershenzon \& Dudareva, 2007).

In Douglas fir, individual trees resistant to feeding by Choristoneura occidentalis seem to contain more monoterpenes (Chen et al., 2002). However, no difference between these trees is detected at the behavioral level: studies show no difference in feeding behavior, a slight deterrence at oviposition (Palermo et al., 2003) and slight differences in fitness (Chen et al., 2002). The authors conclude that monoterpenes do not contribute much to resistance in this system (Clancy, 2002; Cates et al., 2009). Individual $P$. glauca trees that show less C. fumiferana defoliation and hence are considered resistant contain higher foliar monoterpenes (Daoust et al., 2010) as well as toxic phenolics (Delvas et al., 2011). It seems that in this system, the needle surface is involved in a first level of resistance: larvae are less likely to initiate feeding following palpating this resistant foliage (Daoust et al., 2010) and females avoid it in oviposition assays (Mader et al., 2012). Our results suggest that this barrier at the surface of resistant needles is not constituted by their higher concentration of monoterpenes. The role of monoterpenes in P. glauca natural resistance is therefore not obvious.

The role of monoterpenes in conifer-herbivore interactions is multifaceted. Monoterpenes are indeed an effective defense against bark beetles: when the stem is wounded by attacking beetles, the flow of oleoresin traps and drowns the xylophages. As the monoterpenes contained in the resin evaporate, the resin polymerizes to further protect the site of wound. Several monoterpenes are directly toxic to bark beetles - either as volatiles or through contact in oleoresin (Keeling, 2006). However, monoterpenes are also long-range attractants of beetles, and are components in the synthesis of beetle pheromones (Seybold et al., 2006). Monoterpene emissions also attract beetle predators. The role of monoterpenes in interactions with folivorous caterpillars has received less attention: our results show that they stimulate both feeding and oviposition upon contact, suggesting that they play a role in short-range host recognition and selection, and that they interact with the waxes at the needle's surface.

\section{Acknowledgments}

Funding was provided to the iFOR Research Consortium by the Natural Sciences and Engineering Research Council of Canada, the Ministère des Ressources Naturelles et de la Faune du Québec, the Canadian Forest Service and the Societé de Protection des Forêts contre les Insectes et les Maladies du Québec.

\section{Disclosure}

The authors declare that they have no conflict of interest.

\section{References}

Albert, P.J. (1991) A review of some host-plant chemicals affecting the feeding and oviposition behaviours of the 
eastern spruce budworm, Choristoneura fumiferana Clem. (Lepidoptera: Tortricidae). Memoirs of the Entomological Society of Canada, 159, 13-18.

Albert, P.J. and Parisella, S. (1985) Feeding preferences of eastern spruce budworm larvae in two-choice tests with combinations of host-plant extracts. Entomologia Experimentalis et Applicata, 38, 221-225.

Albert, P.J. and Parisella, S. (1988) Physiology of a sucrosesensitive cell on the galea of the eastern spruce budworm larva, Choristoneura fumiferana. Physiological Entomology, 13, 243-247.

Ascoli, A. and Albert, P.J. (1985) Orientation behavior of second-instar larvae of eastern spruce budworm Choristoneura fumiferana (Clem.) (Lepidoptera: Tortricidae) in a Y-type olfactometer. Journal of Chemical Ecology, 11, 837845.

Banga, N., Albert, P.J., Kapoor, N. and McNeil, J.N. (2003) Structure, distribution, and innervation of sensilla on the ovipositor of the spruce budworm, Choristoneura fumifer$a n a$, and evidence of a gustatory function for type II sensilla. Canadian Journal of Zoology, 81, 2032-2037.

Bauce, E., Crépin, M. and Carisey, N. (1994) Spruce budworm growth, development and food utilization on young and old balsam fir trees. Oecologia, 97, 499-507.

Bernays, E.A. (1995) Effects of experience on feeding. Regulatory Mechanisms in Insect Feeding (eds. R.F. Chapman \& G. de Boer), pp. 279-302, Chapman \& Hall, London UK.

Bourdier, T. (2012) Behavioral adaptations of the eastern spruce budworm (Lepidoptera: Tortricidae) to natural white spruce (Picea glauca [Moench]) resistance. M.Sc. Thesis, Concordia University,

Carisey, N. and Bauce, E. (1997) Impact of balsam fir foliage age on sixth-instar spruce budworm growth, development and food utilization. Canadian Journal of Forest Research, 27, 257-264.

Cates, R., Henderson, C. and Redak, R. (1987) Responses of the western spruce budworm to varying levels of nitrogen and terpenes. Oeocologia, 73, 312-316.

Cates, R.G. and Redak, R.A. (1986) Between-year population variation in resistance of Douglas fir to the western spruce budworm. Natural Resistance of Plants to Pests (eds. M.B. Green \& P. Hedin), pp. 106-115. American Chemical Society, Washington.

Cates, R.G., Redak, R.A. and Henderson, C.B. (2009) Natural product defensive chemistry of Douglas fir, western spruce budworm success, and forest management practices. Journal of Applied Entomology, 96, 173-182.

Chen, Z., Kolb, T.E. and Clancy, K.M. (2002) The role of monoterpenes in resistance of Douglas fir to western spruce budworm defoliation. Journal of Chemical Ecology, 28, 897920.
Clancy, K.M. (2002) Mechanisms of resistance in trees to defoliation. Mechanisms and Deployment of Resistance in Trees to Insects (eds. M. Wagner, K. Clancy, F. Lieutier \& T. Paine), pp. 79-103. Kluwer Academic Publishers, The Netherlands.

Daoust, S., Mader, B., Bauce, E., Dussutour, A., Despland, E. and Albert, P. (2010) Influence of epicuticular wax composition on the feeding pattern of a phytophagous insect: implications for host resistance. Canadian Entomologist, 142, 261-270.

Delvas, N., Bauce, É., Labbé, C., Ollevier, T. and Bélanger, R. (2011) Phenolic compounds that confer resistance to spruce budworm. Entomologia Experimentalis et Applicata, 141, 3544.

Eigenbrode, S. and Espelie, K. (1995) Effects of plant epicuticular lipids on insect herbivores. Annual Review of Entomology, 40, 171-194.

Espelie, K., Bernays, E.A. and Brown, J. (1991) Plant and insect cuticular lipids serve as behavioral cues for insects. Archives of Insect Biochemistry and Physiology, 17, 223-233.

Fuentealba, A. and Bauce, E. (2012) Carryover effect of host nutritional quality on performance of spruce budworm progeny. Bulletin of Entomological Research, 102, 275-284.

Gershenzon, J. and Dudareva, N. (2007) The function of terpene natural products in the natural world. Nature Chemical Biology, 3, 408-414.

Gordon, D.P., Percy, K.E. and Riding, R. (1998) Effects of UV-B radiation on epicuticular wax production and chemical composition of four Picea species. New Phytologist, 138, 441-449.

Grant, G.G., Guo, J., MacDonald, L. and Coppens, M.D. (2007) Oviposition response of spruce budworm (Lepidoptera: Tortricidae) to host terpenes and green-leaf volatiles. Canadian Entomologist, 139, 564-575.

Grant, G.G. and Langevin, D. (1994) Oviposition responses of four Choristoneura (Lepidoptera: Tortricidae) species to chemical and physical stimuli associated with host and nonhost foliage. Environmental Entomology, 23, 447-456.

Grant, G.G., Zhao, B. and Langevin, D. (2000) Oviposition response of spruce budworm (Lepidoptera: Tortricidae) to aliphatic carboxylic acids. Environmental Entomology, 29, 164-170.

Grisdale, D.G. and Wilson, G.G. (1988) A laboratory method of mass rearing the eastern spruce budworm Choristoneura fumiferana. Advances and Challenges in Insect Rearing (eds. E. King \& N. Leppla), pp. 223-231. U.S. Department of Agriculture Technical Bulletin, New Orleans.

Hanover, J. (1975) Physiology of tree resistance to insects. Annual Review of Entomology, 20, 75-95.

Hellen, H., Tykka, T. and Hakola, H. (2012) Monoterpenes and isoprene in urban air in Helsinki, Finland. Geophysical Research Abstracts, 14, 4028. 
Huber, D.W., Ralph, S. and Bohlmann, J. (2004) Genomic hardwiring and phenotypic plasticity of terpenoid-based defenses in conifers. Journal of Chemical Ecology, 30, 2399-2418.

Keeling, C.I. and Bohlmann, J. (2006) Genes, enzymes and chemicals of terpenoid diversity in the constitutive and induced defence of conifers against insects and pathogens. New Phytologist, 170, 657-675.

Keeling, C.I., Weisshaar, S., Ralph, S.G., Jancsik, S., Hamberger, B., Dullat, H.K. and Bohlmann, J. (2011) Transcriptome mining, functional characterization, and phylogeny of a large terpene synthase gene family in spruce (Picea spp.). BMC Plant Biology, 11, 43-57.

Kumbasli, M. and Bauce, E. (2013) Spruce budworm biological and nutritional performance responses to varying levels of monoterpenes. iForest, 6, 310-314.

Lerdau, M., Litvak, M., Palmer, P. and Russell, M. (1997) Controls over monoterpene emissions from boreal forest conifers. Tree Physiology, 17, 563-569.

Mader, B., Daoust, S.P., Bauce, E. and Despland, E. (2012) Larval experience induces adult aversion to rearing host plants: a novel behaviour contrary to Hopkins' host selection principle. Ecological Entomology, 37, 204-211.

Maloney, P.J., Albert, P.J. and Tulloch, A.P. (1988) Influence of epicuticular waxes from white spruce and balsam fir on feeding behavior of the eastern spruce budworm. Journal of Insect Behavior, 1, 197-208.

Matas, A., Sanz, M. and Heredia, A. (2003) Studies on the structure of the palnt wax nonacosan-10-ol, the main component of epicuticular wax conifers. International Journal of Biological Macromolecules, 33, 31-35.

Mattson, W.J., Haack, R.A., Lawrence, R.K. and Slocum, S.S. (1991) Considering the nutritional ecology of the spruce budworm and its management. Forest Ecology and Management, 39, 183-210.

Muller, C. and Riederer, M. (2005) Plant surface properties in chemical ecology. Journal of Chemical Ecology, 31, 26212651.

Palermo, B.L., Clancy, K.M. and Koch, G.W. (2003) Feeding and oviposition behavior do not explain Douglas-fir resistance to defoliation by the western spruce budworm (Lepidoptera: Tortricidae). Environmental Entomology, 32, 626632.
Powell, J.S. and Raffa, K. (2003) Fate of conifer terpenes in a polyphagous folivore: evidence for metabolism by gypsy moth (Lepidoptera: Lymantriidae). Journal of Entomological Science, 38, 583-601.

Pruegel, B. and Lognay, G. (1996) Composition of the cuticular waxes of Picea abies and P. sitchensis. Phytochemical Analysis, 7, 29-36.

Redak, R. and Cates, R.G. (1984) Douglasfir (Pseudostuga menziesii)-spruce budworm (Choristoneura occidentalis) interactions: the effect of nutrition, chemical defenses, tissue phenology, and tree physical parameters on budworm success. Oecologia, 62, 61-67.

Rivet, M.P. and Albert, P.J. (1990) Oviposition behavior in spruce budworm Choristoneura fumiferana (Clem.) (Lepidoptera: Tortricidae). Journal of Insect Behavior, 3, 395-400.

Seybold, S., Huber, D., Lee, J., Graves, A. and Bohlmann, J. (2006) Pine monoterpenes and pine bark beetles: a marriage of convenience for defense and chemical communication. Phytochemistry Review, 5, 143-178.

Städler, E. (1974) Host plant stimuli affecting oviposition behavior of the eastern spruce budworm. Entomologia Experimentalis et Applicata, 17, 176-188.

Steinbauer, M.J.S., Schiestl, F.P. and Davies, N.W. (2004) Monoterpenes and epicuticular waxes help female autumn gum moth differentiate between waxy and glossy Eucalyptus and leaves of different ages. Journal of Chemical Ecology, 30, 1117-1142.

Tingey, D., Turner, D. and Weber, J. (1991) Factors controlling the emissions of monoterpenes and other volatile organic compounds. Trace Gas Emissions by Plants (eds. T. Sharkey, E. Holland \& H. Mooney), pp. 93-115. Academic Press, San Diego.

Wallace, E.K., Albert, P.J. and McNeil, J.N. (2004) Oviposition behavior of the eastern spruce budworm Choristoneura fumiferana (Clemens) (Lepidoptera: Tortricidae). Journal of Insect Behavior, 17, 145-154.

Wallin, K. and Raffa, K. (2002) Prior encounters modulate subsequent choices in host acceptance behavior by the bark beetle Ips pini. Entomologia Experimentalis et Applicata, 103, 205218.

Accepted June 7, 2015 